\title{
Comparison of Energy Expenditure during Walking between Female Athletes and Non-Athletes
}

\author{
Fariba Hossein Abadi ${ }^{1,2}$, Tajul Ariffin Muhamad ${ }^{1}$, Norlena Salamuddin ${ }^{1}$, Mohd Radzani ${ }^{1} \&$ Hasti Satari $^{1}$ \\ ${ }^{1}$ Faculty of Education, Universiti Kebangsaan Malaysia, Selangor, Malaysia \\ ${ }^{2}$ Faculty of Physical Education, Shahid Rajaee Teacher Training University, Lavizan, Tehran, Iran \\ Correspondence: Fariba Hossein Abadi, Faculty of Physical Education, Shahid Rajaee Teacher Training \\ University, Lavizan, Tehran, 16788-15811, Iran. E-mail: far_hos@yahoo.com
}

Received: August 16, $2013 \quad$ Accepted: October 14, $2013 \quad$ Online Published: November 28, 2013
doi:10.5539/ass.v9n16p40

\begin{abstract}
This study aimed to determine, if there is a difference in energy expenditure during walking among athletes and non-athletes at two different speeds of walking. Ninety five healthy female students (47 athletes and 48 non-athletes) with a mean age of $22.4( \pm 1.6)$ years purposively participated in this study. Medical and sport participation history of the subjects was acquired through a questionnaire. Two experimental tests including anthropometric measurements, $\dot{\mathrm{V}} \mathrm{O}_{2 \max }$, and walking tests on treadmill at speeds of 3.00 and $3.5 \mathrm{mph}$ were conducted. Results showed no difference in weight, height, body mass index, and leg length between both groups. The non-athletes expended a greater amount of energy than athletes $\left(3.78 \pm .1\right.$ and $2.95 \pm .6 \mathrm{kcal}^{\mathrm{min}}{ }^{-1}$, respectively) at both speeds of $3.00 \mathrm{mph}$ and $3.5 \mathrm{mph}\left(4.89 \pm 1\right.$ and $\left.3.94 \pm .7 \mathrm{kcal} . \mathrm{min}^{-1}\right)$. Based on energy requirements for walking at similar weights and speeds by ACSM's guideline, the female athletes walked at a slow, moderate and brisk pace. Most of the female non-athletes walked at a moderate, brisk and very brisk pace. This study revealed that regular exercise could improve walking efficiency, and the energy expenditure of walking would play an important role in the information processing for total energy requirement that progressively affects weight management and health.
\end{abstract}

Keywords: energy expenditure, walking, female, athletes

\section{Introduction}

Walking is the most common physical activity in daily life performed by both sedentary and active people. It is an easy, simple, accessible and pleasurable activity to do in order to improve fitness levels. Hence, assessing walking energy expenditure is a valid way to determine walking efficiency, control or reduce weight, body composition and fitness of individuals (Macpherson, Purcell, \& Bulley, 2009; Waters \& Mulroy, 1999). Moreover, many studies report significant health benefits from brisk walking $(+3 \mathrm{mph})$ for two or more hours per week, with greater benefits resulting from faster walking or longer durations (Krinski, Elsangedy, Krause, Timossi \& Silva, 2012; Howley, 2001). Although the American College of Sports Medicine (ACSM) recommended the METs value for brisk walking on flat and hard surface at the speed of 3.0- 3.5mph (3 and 4METs) as a moderate level of intensity for physical activity (ACSM, 2009), other researches revealed the energy cost of walking is higher for non-active than active adults across different walking speeds (Martin, Rothstein \& Larish, 1992). In fact, an active male can successfully enhance walking efficiency, and increases endurance in walking, running and trekking not only without any harm to his health or function but also will increase his capacity to support specific effort ( Peterson \& Martin, 2010).

According to McArdle et al. (2006), older adults who participate in 20 to 30 minutes of moderate-intensity exercise on most days of the week have better physical function, e.g. endurance, lower extremity strength, gait speed and balance, than older persons who are inactive or active throughout the day but do not exercise. However, even if exercise has not been a lifelong habit, researches show that adults who participate in sports and physical activity in old age have better postural ability than adults who only exercised at early age (Rose \& Gamble, 2006). Similarly, Studenski, et al. (2011) reported that the best walking speed is chosen based on body abilities. Accordingly, any imbalance of these systems is likely to cause increment in physiologic penalties, or energy cost. 
However, previous literatures lack sufficient sources to distinguish the difference of energy expenditure of walking among different people and specifically in women (Krinski et al., 2012). As long as people naturally walk in the manner that conserves energy at speed of 1.2 to $1.5 \mathrm{~m} . \mathrm{s}^{-1}$ (Dal et al. 2010; Alexander, 2002), it can be promising to find if there is any significant difference in energy cost of walking for athletes and non-athletes, as active and non-active people respectively. In particular, there is no study reported to investigate the energy expenditure of walking among athletes and non-athletes. For these reason, the aim of this investigation is to describe the difference of walking efficiency between female athletes and non-athletes at two different speeds; 3.0 and $3.5 \mathrm{mph}$. This study will bring to light the effectiveness of regular exercise during sport activities on walking efficiency as well as the other health aspects affecting the body of females.

\section{Method}

Ninety five healthy females (47 athletes and 48 non-athletes) aged 20-25 years $(22.4 \pm 1.5)$ purposively participated in the experiment, each given her informed consent before the experiment began. All non-athlete subjects have not been involved in regular exercise, physical activities or play sports in their daily life. The samples for athletes were chosen from UKM sport team players who had a background of regularly exercising for minimum of twice a week for the past three years. They were introduced and recommended through UKM coach of sport teams. Students doing non- active sports and cognitive task sports (like archery) were not included in this study.

All the athlete subjects had the mean of $6.2( \pm 3.5)$ years' participation in sports activity and an average of $3( \pm 0.6)$ exercise sessions per week. All participants were advised to avoid taking meals or consume any products with caffeine 2 hours before the tests. They had not taken drugs, pills and alcohol during the last 24 hours before the test. They were non-pregnant and non-lactating women. Information regarding to subject's age, physical activity and athletic background, medical history and current medical status were obtained from subjects by means of questionnaire. Physical characteristics such as body mass, height, BMI, leg length and resting heart rate $\left(\mathrm{HR}_{\text {rest }}\right)$ of the participants were shown in Table 1. Leg lengths for both legs were measured from greater trochanter to lateral malleolus. Resting heart rate was obtained by Heart rate Monitor after 7 minutes of rest in the supine position. The $\mathrm{V}_{2 \max }$ was obtained using Queen's College step test (QCT) protocol as a submaximal exercise protocol.

\subsection{Procedure}

Before starting the exercise protocol, each subject was familiarized with the treadmill. The experiment was conducted in four phases. Firstly, the participants were asked to walk at their own natural pace which was considered as a casual walking, along the straight line of $20 \times 1 \mathrm{~m}$ walk way to measure stride length (SL) and step width (SW). These gait parameters were measured in order to control the basic gait factor differences among each group. Subjects were given two trails. At the second stage, participants walked using their own style of walking gait for 8 minutes at the speed of $3.0 \mathrm{mph}$ on the treadmill. Each subject wore Polar Transmitter and Elastic Snap at the level of xiphoid process, and the Pedometer (YAMAX DIGI WALKER) at the left side of waist to measure the cadences while HR was measured during walking on treadmill. Wrist Monitor was worn by investigator who stayed within 3 to 3.5 feet (maximum $1 \mathrm{~m}$ ) by the subjects. HR measured by averaging the HR at respective 10 -seconds interval during last 4 minutes ( $4^{\text {th }}$ to $8^{\text {th }}$ minutes) was recorded. Right at the end of test, before leaving treadmill, the cadences (step frequency) recorded by pedometer monitor were noted. At the third stage, similar to the second stage, each participant walked at the speed of $3.5 \mathrm{mph}$. This test was completed after HR recovery, and the subjects rested at least 10 minutes prior to the next walking test to avoid effect of fatigue. At the last stage, after HR recovery, submaximal Queen's College step test (QCT) protocol was conducted to measure $\dot{\mathrm{V}} \mathrm{O}_{2 \max }$. Elevation of the treadmill set at $0 \%$ grade. No subjects were allowed to hold onto the handrails.

\subsection{Energy Expenditure Computing}

Data collected were processed and used to compute energy expenditure using the following approach;

Energy expenditure in kcal. $\mathrm{min}^{-1}$ was computed from the participants' walking $\mathrm{HR}$ and converting to $\mathrm{V}_{2}$ procedure. Recorded HR values were transformed into $\% \mathrm{HRR}$ values by utilizing the formula: $\% \mathrm{HRR}=$ [(activity HR - resting HR)/ (est. $\mathrm{HR}_{\max }$ - resting HR)] $\times 100 \%$ where $\mathrm{HR}_{\max }$ was assumed to equal [206.9-(0.67 $\times$ age)] (ACSM, 2009). Taking into consideration that \%HRR is approximately equal to the $\% \dot{\mathrm{VO}}{ }_{2}$ reserve, the relative intensity of the walking bout was determined. Then, $\% \mathrm{VO}_{2}$ reserve for each activity was transformed to absolute oxygen consumption $\left(\mathrm{V}_{2} \mathrm{ml}_{\mathrm{kg}}{ }^{-1} \cdot \mathrm{min}^{-1}\right)$ using following formula (1) (Kang, 2008):

$$
\dot{V} \mathrm{O}_{2} \text { reserve }=\left[\left(\text { activity } \dot{V} \mathrm{O}_{2}-\text { resting } \dot{\mathrm{V}} \mathrm{O}_{2}\right) /\left(\text { est. } \dot{V} \mathrm{O}_{2 \max }-\text { resting } \dot{\mathrm{V}} \mathrm{O}_{2}\right)\right] \times 100 \%
$$

where $\dot{\mathrm{VO}}_{2 \max }$ was obtained from QCT. Furthermore, EE $\left(\mathrm{kcal} \cdot \mathrm{min}^{-1}\right)$ was estimated as $\dot{\mathrm{V}} \mathrm{O}_{2}\left(\mathrm{ml} \cdot \mathrm{kg}^{-1} \cdot \mathrm{min}^{-1}\right) \times$ 
Weight $\times 5.05) / 1000\left({\mathrm{kcal} . \mathrm{LO}_{2}}^{-1}\right)$, and $\dot{\mathrm{V}}_{2}$ also was converted to METs by dividing by 3.5$)(\mathrm{Kang}$, 2008; Swain, 1998). In order to calculate the gait parameters, the following walking speed formula (2) was used (Rose $\&$ Gamble, 2006):

$$
\text { Walking Speed }\left(m . s^{-1}\right)=\text { stride length } \times \text { stride frequency }(\text { cadence } \times 2)
$$

Whereby stride length (SL) is calculated by: Walking Speed/ (cadence $\times 2$ ). The calculated speed in units of mph was converted to units of $\mathrm{m} . \mathrm{s}^{-1}$ to be used for this formula.

\subsection{Data Analysis}

Data were analyzed using SPSS 20.0 statistical software with probability of significant set at $p \leq$ 0.05.Descriptive and inferential statistical analysis techniques were used to examine for differences between the EE of walking of athlete and non-athlete females. Differences between the mean of EE (kcal.min ${ }^{-1}$ ) and METs during two speeds (3.0 and $3.5 \mathrm{mph}$ ) were compared statistically with the t-test.

\section{Results}

The demography values of subject characteristics are illustrated in Table 1. While the difference between the average of $\mathrm{HR}_{\text {rest }}$ and $\dot{\mathrm{V}} \mathrm{O}_{2 \text { max }}$ were statistically significant $(\mathrm{p}<.005)$, there was no significant difference in weigh, height, BMI, and leg length between athlete and no-athlete females $(\mathrm{p}<.005)$.

Table 1. Demographic values (Mean $\pm \mathrm{SD})$ of subjects' characteristics

\begin{tabular}{|c|c|c|c|c|c|c|c|c|}
\hline Group & $\begin{array}{l}\text { Weight } \\
\mathrm{kg}\end{array}$ & $\begin{array}{l}\text { Height } \\
\mathrm{cm}\end{array}$ & $\begin{array}{l}\text { BMI } \\
\text { kg.m }{ }^{-2}\end{array}$ & $\begin{array}{l}\text { Leg } \\
\text { length } \mathrm{cm}\end{array}$ & $\begin{array}{l}\mathrm{HR}_{\text {rest }} \\
\text { bmp }\end{array}$ & 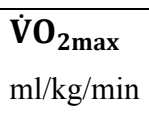 & $\begin{array}{l}\text { HRW1 } \\
\text { bpm }\end{array}$ & $\begin{array}{l}\text { HRW2 } \\
\text { bpm }\end{array}$ \\
\hline $\begin{array}{l}\text { Athletes } \\
(\mathrm{N}=47)\end{array}$ & $53.7 \pm 7.1$ & $159.0 \pm 5.9$ & $21.2 \pm 2.4$ & $77.8 \pm 4.1$ & $62.7 \pm 4.7$ & $40.9 \pm 2.0$ & $98.9 \pm 6.01$ & $115.5 \pm 8.5$ \\
\hline $\begin{array}{l}\text { Non-athlete } \\
(\mathrm{N}=48)\end{array}$ & $56.8 \pm 11.6$ & $157.2 \pm 5.5$ & $23.0 \pm 4.3$ & $76.9 \pm 4.1$ & $73 . \pm 6.0$ & $34.8 \pm 2.2$ & $118.1 . \pm 9.5$ & $142 . \pm 11.03$ \\
\hline
\end{tabular}

Note: HRW1= heart rate of walking at speed of 3.0; HRW2= heart rate of walking at speed of $3.5 \mathrm{mph}$

Table 2 shows the information of gait parameters measured during the normal and comfortable walking on the ground, and walking on the treadmill at speeds 3.0 and $3.5 \mathrm{mph}$. Athletes had significantly $(\mathrm{p}<.005)$ longer stride length during walking on the ground (at comfortable pace and their own speed) and on the treadmill at both speeds. Non -athletes had significantly higher stride frequency $\left(58.7 \pm 2.5,63.1 \pm 2.1 \mathrm{~S} . \mathrm{min}^{-1}\right)$, at speeds of 3.0 and $3.5 \mathrm{mph}$ respectively, compare to athlete females $\left(57.1 \pm 2.6,61.1 \pm 2{\mathrm{~S} . \mathrm{min}^{-1}}^{-1}\right.$. In other words, non-athlete females had shorter stride length than athletes and accordingly, non-athletes need to have more stride frequency to maintain the same walking speed. There was no significant difference in step width between athlete $(6.2 \pm 1.3$ $\mathrm{cm})$ and non-athletes $(6.6 \pm 1.9 \mathrm{~cm})$.

Table 2. Gait parameters (Mean \pm SD) during walking: on the ground and treadmill

\begin{tabular}{lllllll}
\hline Group & $\begin{array}{l}\text { Step } \\
\text { width } \\
\mathrm{cm}\end{array}$ & $\begin{array}{l}\text { Stride length } \\
\text { on ground } \\
\mathrm{m}\end{array}$ & $\begin{array}{l}\text { Stride } \\
\text { length } 1\end{array}$ & $\begin{array}{l}\text { Stride } \\
\text { length } 2 \\
\mathrm{~m}\end{array}$ & $\begin{array}{l}\text { Stride } \\
\text { frequency 1 } \\
\text { S.min }^{-1}\end{array}$ & $\begin{array}{l}\text { Stride } \\
\text { frequency } 2 \\
\text { S.min }^{-1}\end{array}$ \\
\hline $\begin{array}{llllll}\text { Athletes } \\
\text { Non-athlete }\end{array}$ & $6.2 \pm 1.3$ & $1.33 \pm 0.07$ & $1.35 \pm 0.04$ & $1.51 \pm 0.05$ & $57.1 \pm 2.6$ & $61.1 \pm 2$ \\
\hline
\end{tabular}

$1=$ walking at speed of $3.0 ; 2=$ walking at speed of $3.5 \mathrm{mph}$. 
Table 3. Comparing EE and METs values of walking at speeds of 3.0 and 3.5

\begin{tabular}{llllll}
\hline $\begin{array}{l}\text { Speed } \\
(\mathrm{mph})\end{array}$ & Variables & $\begin{array}{l}\text { Athlete } \\
(\mathrm{N}=47)\end{array}$ & Non-athlete $(\mathrm{N}=48)$ & t-value & $p$ \\
\hline \multirow{3}{*}{3.0} & EE $\left(\mathrm{kcal} . \mathrm{min}^{-1}\right)$ & $2.95 \pm .54$ & $3.78 \pm 1.0$ & 2.25 & .027 \\
& METs & $3.12 \pm .38$ & $3.74 \pm .47$ & 7.02 & .000 \\
3.5 & EE $\left(\mathrm{kcal} . \mathrm{min}^{-1}\right)$ & $3.94 \pm .72$ & $4.89 \pm 1.07$ & 5.07 & .000 \\
\hline
\end{tabular}

As illustrated in Table 3, not only EE of walking of non - athletes $\left(3.78 \pm 1.0 \mathrm{kcal} . \mathrm{min}^{-1}\right)$ was significantly higher than female athletes $\left(2.95 \pm .54 \mathrm{kcal}_{\mathrm{min}} \mathrm{m}^{-1}\right)$, at the speed of $3.0 \mathrm{mph}(\mathrm{p}<.005)$, but it was statistically significant at the speed of $3.5 \mathrm{mph}$ with $3.94 \pm .72$ and $4.89 \pm 1.07 \mathrm{kcal} . \mathrm{min}^{-1}$, respectively $(\mathrm{p}<.001)$. In addition, METs values of athletes ( $3.12 \pm .38$ METs) was lower than non-athletes $(3.74 \pm .47$ METs) at the speed of $3.0 \mathrm{mph}(\mathrm{p}<$. 001). Moreover, a significant difference in METs values between athlete (4.14 .45 METs) and non-athlete $(4.9 \pm .51 \mathrm{METs})$ at the speed of $3.5 \mathrm{mph}(\mathrm{p}<.001)$ was observed.

Based on the findings, female athletes walked as at a slow and moderate pace $(40.4 \%$ of them expend METs $<3$ and $59.6 \%$ expend $3-4$ METs) at the speed of $3.0 \mathrm{mph}$, whereas $71 \%$ and $23 \%$ of female non-athlete walked at moderate and brisk (4-5METs) walking pace, respectively. At the speed of $3.5 \mathrm{mph}, 38 \%$ and $56 \%$ of female athletes walked at a moderate pace and brisk walking pace, while most of the female non-athletes walked at brisk and very brisk walking pace with $62.5 \%$ and $25 \%$, respectively.

\section{Discussion}

Evaluation of walking energy expenditure is potentially useful for quantifying and differentiating the walking efficiency, and it can be accurately investigated to promote weight maintenance. Hence, in order to make walking an activity for health and weight control, its energy expenditure should be measured accurately (Browning et al., 2006).

The findings of the present study demonstrated that the female athletes expended less energy during walking at speeds 3.0 and $3.5 \mathrm{mph}$ than female non-athletes, as shown in Table 3. These results suggest that the physical activity background has an important role in minimizing energy expenditure of walking. In other word, females with regular exercise background have more walking efficiency compare to the ones with no physical activity background.

Unfortunately, no research is available regarding to the energy expenditure of walking or economical walking speed among female athletes, but according to Dal et al. (2010) that presents walking at a speed of $71.15 \pm 13.85$ $\mathrm{m} \cdot \mathrm{min}^{-1}(\sim 2.7 \mathrm{mph})$ was the economical speed for both genders, it seems that female athlete walked more efficiently at that speed. Even though female athlete participants in this study expended higher energy at the speed of $3.5 \mathrm{mph}$, they particularly expended less energy during walking at the speed of $3.0 \mathrm{mph}$ compared with the energy cost of walking for similar speeds reported in other studies (Thomas et al., 2009; Minetti et al., 2001).

Furthermore, the energy expenditure of walking in female athletes at the speed of $3.0 \mathrm{mph}$ indicated less expended energy compared to the energy cost of walking categorized based on body weight by Howley and Franks (2007). Similarly, the female athlete subjects expend less METs values $(3.12 \pm .4)$ than ASCM's recommendation reports while walking at the speed of approximately $3.0 \mathrm{mph}$ (Pate et al., 2007). Based on METs equivalents of common physical activities classified by ACSM's report, the pace of walking of female athletes is considered as the light intensity physical activity. Female athletes expend $4.14 \pm .45$ METs while walking at the speed of $3.5 \mathrm{mph}$, which is classified as moderate intensity physical activity.

The results for female non-athletes showed that the energy expenditure of walking at the speed of $3.0 \mathrm{mph}$, based on body weight, is similar to the result reported by Howley and Franks (2007) for walking at the speed of $3.5 \mathrm{mph} ; 94 \mathrm{~m} . \mathrm{min}^{-1}$. However, it must be noted that the average mean of energy expenditure and efficiency of walking for the young healthy female non-athletes are likely very different compare to the other reported results for various populations in similar studies.

On the other hand, there was no significant difference in weight between selected female athletes and non-athletes; $53.7 \pm 7.1$ and $56.8 \pm 11.6 \mathrm{~kg}$, respectively. Therefore, the difference of energy expenditure between athlete and non-athlete participants probably depends on the number and the speed of muscular contraction as combination of stride length and stride frequency, during a period of walking. Furthermore, there 
are evidences indicating that the effecting factors are not limited to weight, body mass distribution and load carriage (McArdle et al., 2006) and, physical activity level and energy efficiency of muscles can considerably influence the energy cost of walking (Manini, 2010).

In the present study, female athletes walking at the speed of $3.0 \mathrm{mph}$ have the stride length of $1.34 \pm .04 \mathrm{~m}$ and the stride frequency of $57.08 \pm 2.6 \mathrm{~S}_{\mathrm{min}}{ }^{-1}$, while for female non-athlete's stride length and the stride frequency were $1.31 \pm .06 \mathrm{~m}$ and $58.63 \pm 2.5{\mathrm{~S} . \mathrm{min}^{-1}}^{-1}$ respectively. Thus, walking with increasing in stride frequency could cause greater energy expenditure in this speed. Similarly, Kito et al. (2006) suggested that in casual walk, cycle duration is the dominant factor rather than stride length to minimize energy expenditure. The findings of our study are in agreement with the study by Kuo (2001) and Doke, et al. (2005). Then, the reason for large increase in energy expenditure for female non-athletes may be explained by substandard $\dot{\mathrm{V}}_{2 \max }$ higher resting heart rate, step frequency increment and shorter stride length compare to their natural stride length on the ground.

According to the findings of the mean average of walking energy expenditure per minute and the stride frequency per minute at the speed of $3.0 \mathrm{mph}$ is categorized as a brisk walking. Then, an average of 3500 to 4000 strides $\left(\sim 220 \mathrm{kcal}^{-d a y}{ }^{-1}\right)$ is recommended per hour for five days per week for female non-athletes. During these amounts of stride walking activity, they will approximately expend $1000 \mathrm{kcal}$ per week, which is equal to ACSM's Guidelines for Exercise Testing and Prescription (2009) for engaging in regular sustained physical activity of moderate intensity.

Findings of the current study also suggest that estimation of energy expenditure of walking plays an important role in information processing in total energy requirement which progressively and slowly effect on weight management and health (Howley \& Franks, 2007; Brown \& Holloszy, 1993; Driskell \& Wolinsky, 2009). This study tries to point out the fact that the athletes tend to gain weight effortlessly during rest seasons. It also supports the suggestion to keep the athletes aware of estimating total daily energy requirements to manage their weight, especially after the end of competitive season or in the older ages.

\section{Conclusion}

Conclusively, the findings of this study demonstrate that the female athletes expended less energy during walking and the physical activity background has an important role in minimizing energy expenditure during walking. Females with regular exercise background have more efficiency of walking compare to the ones with no regular exercise and physical activity background. The differences in energy expenditure of walking between athlete and non-athlete females are explained with regard to the difference in muscular efficiency, or fitness levels.

\section{Acknowledgements}

This research was supported by Faculty of Education and Sport Centre of National university of Malaysia (Universiti Kebangsaan Malaysia). The authors wish to thank Dr. Mohd. Radzani Abd. Razak, for his insightful comments and all the subjects for participation.

\section{References}

ACSM's. (2009). American College of Sports Medicine: Guidelines for Exercise Testing and Prescription (8th ed.). Wolter Kluwer, Lippincott Williams \& Wilkins.

Alexander, M. N. (2002). Energetics and optimization of human walking and running. Am J Hum Biol, 14(5), 641-648. http://dx.doi.org/10.1002/ajhb.10067

Brooks, A.G., Gunn, S. M., Withers, R. T., Gore, C. J., \& Plummer, J. L. (2005). Predicting walking METs and energy expenditure from speed or accelerometry. Med. Sci. Sports Exerc., 37(7), 1216-1223. http://dx.doi.org/10.1249/01.mss.0000170074.19649.0e

Brown, M., \& Holloszy, J. (1993). Effect of walking, jogging and cycling on strength, flexibility, speed and balance in 60 to 72 years old. Aging (Milano), 5(6), 427-234.

Browning, R., Browning, C. R., Baker, E. A., Herron, J. A., \& Kram, R. (2006). Effects of obesity and sex on the energetic cost and preferred speed of walking. J. Appl. Physiol., 100(2), 390-398. http://dx.doi.org/10.1152/japplphysiol.00767.2005

Dal, U., Erdogan, T., Resitoglu, B., \& Beydagi, H. (2010). Determination of preferred walking speed on treadmill may lead to high oxygen cost on treadmill walking. Gait Posture, 31(3), 366-369. http://dx.doi.org/10.1016/j.gaitpost.2010.01.006

Doke, J., Donelan, J. M., \& Kuo, A. D. (2005). Mechanics and energetics of swinging the human leg. J. Exp. Biol., 208(3), 439-445. http://dx.doi.org/10.1242/jeb.01408

Driskell, J. A., \& Wolinsky, I. (2009). Nutritional Concerns in Recreation, Exercise, and Sport (1st ed.). CRC 
Press, Taylor \& Francis Group.

Howley, E. T. (2001). Type of activity: Resistance, aerobic and leisure versus occupational physical activity. Med. Sci. Sports Exerc., 33(6), 364-369. http://dx.doi.org/10.1097/00005768-200106001-00005

Howley, E. T., \& Franks, B. D. (2007). Fitness professional's handbook. Human Kinetics.

Jurca, R., Jackson, A. S., LaMonte, M. J., Morrow, J. R., Blair, S. N., Wareham, N. J., ... Jakicic, J. M. (2005). Assessing cardiorespiratory fitness without performing exercise testing. Am. J. Prev. Med., 29(3), 185-193. http://dx.doi.org/10.1016/j.amepre.2005.06.004

Kang, J. (2008). Bioenergetics Primer for Exercise Science (1st ed.). Human Kinetics.

Kito, T., \& Yoneda, T. (2006). Dominance of gait cycle duration in casual walking. Hum Movement Sci, 25(3), 383-392. http://dx.doi.org/10.1016/j.humov.2006.01.001

Krinski, K., Elsangedy, H. M., Krause, M. P., Timossi, L. S., \& Silva, S.G. (2012). Comparison of energy cost between genders during treadmill walking at a self-selected pace. Acta Sci. Health Sci., 34(2), 145-150. http://dx.doi.org/10.4025/actascihealthsci.v34i2.9333

Kuo, A. D. (2001). A simple model of bipedal walking predicts the preferred speed-step length relationship. $J$. Biomech. Eng., 124, 113-120. http://dx.doi.org/10.1115/1.1427703

Macpherson, C., Purcell, C., \& Bulley, C. (2009). Energy expended when walking 10,000 steps at different speeds. Adv Physiother, 11(4), 179-185. http://dx.doi.org/10.3109/14038190903214530

Manini, T. M. (2010). Energy expenditure and aging. ARR, 9(1), 1-11. http://dx.doi.org/10.1016/j.arr.2009.08.002

Martin, P. E., Rothstein, D. E., \& Larish, D. D. (1992). Effects of age and physical activity status on the speed-aerobic demand relationship of walking. J. Appl. Physiol., 73(1), 200-206.

McArdle, W. D., Katch, F. I., \& Katch, V. L. (2006). Essentials of Exercise Physiology (1st ed.). Lippincott Williams \& Wilkins.

Minetti, A. E., Lucap, A., Capodaglio, E. M., \& Saibene, F. (2001). Energetics and mechanics of human walking $\begin{array}{lllll}\text { at oscillating } & \text { speeds. } & \text { Zool., } & 41(2), & \text { 205-210. }\end{array}$ http://dx.doi.org/10.1668/0003-1569(2001)041[0205:EAMOHW]2.0.CO;2

Pate, R. R., Pratt, M., Blair, S. N., Haskell, W. L., Macera, C. A., Bouchard, C., .. King, A. C. (2007). Physical activity and public health, updated recommendation for adults from the American College of Sports Medicine and the American Heart Association. J. Am. Med. Assoc., 273(5), 402-407. http://dx.doi.org/10.1001/jama.1995.03520290054029

Peterson, D. S., \& Martin, P. E. (2010). Effects of age and walking speed on coactivation and cost of walking in healthy adults. Gait Posture, 31(3), 355-359. http://dx.doi.org/10.1016/j.gaitpost.2009.12.005

Rose, J., \& Gamble, J. G. (2006). Human Walking (3rd ed.). Lippincott Williams \& Wilkins.

Strath, S. J., Swartz, A. M., Bassett, D. R., O'brien, W. L., King, G. A., \& Ainsworth, B. E. (2000). Evaluation of heart rate as a method for assessing moderate intensity physical activity. Med. Sci. Sports Exerc., 32(9), 465-470. http://dx.doi.org/10.1097/00005768-200009001-00005

Studenski, S., Perera, S., Patel, K., Rosano, C., Faulkner, K., Inzitari, M., ... Connor, E. B. (2011). Gait speed and survival in older adults. J. Am. Med. Assoc., 305(1), 50-54. http://dx.doi.org/10.1001/jama.2010.1923

Swain, D. P., Leutholtz, B. C., King, M. E., Hass, L. A., \& Branch, J. D. (1998). Relationship between \% heart rate reserve and \% VO2 reserve in treadmill exercise. Med. Sci. Sports Exerc., 30(2), 318-321. http://dx.doi.org/10.1097/00005768-199802000-00022

Thomas, S. S., Buckon, C. E., Schwartz, M. H., Sussman, M. D., \& Aiona, M. D. (2009). Walking energy expenditure in able-bodied individuals: A comparison of common measures of energy efficiency. Gait Posture, 29(4), 592-596. http://dx.doi.org/10.1016/j.gaitpost.2009.01.002

Waters, R. L., \& Mulroy, S. (1999). The energy expenditure of normal and pathologic gait. Gait Posture, 9(3), 207-231. http://dx.doi.org/10.1016/S0966-6362(99)00009-0

Willis, W. T., Ganley, K. J., \& Herman, R. M. (2005). Fuel oxidation during human walking. Metabolism, 54(6), 793-799. http://dx.doi.org/10.1016/j.metabol.2005.01.024

\section{Copyrights}

Copyright for this article is retained by the author(s), with first publication rights granted to the journal.

This is an open-access article distributed under the terms and conditions of the Creative Commons Attribution license (http://creativecommons.org/licenses/by/3.0/). 